\title{
Asymmetric bio-epoxidation catalyzed with the styrene monooxygenase from Pseudomonas sp. LQ26
}

\author{
Yan Liư ${ }^{1,2,3}$, Yu-Chang Liu ${ }^{1,2,3}$ and Zhong-Liu Wu ${ }^{1,2^{*}}$
}

\begin{abstract}
Styrene monooxygenases (SMOs) can catalyze the asymmetric epoxidation of alkenes to obtain optically active epoxides. This account describes a series of work of our group on the isolation, application, and improvement of an SMO from Pseudomonas sp. LQ26. The strain was isolated from an active sludge sample based on indigo-forming capacity. Then the gene encoding SMO was expressed in Escherichia coli, and the whole cells were applied in biocatalytic reactions. The substrate spectrum of SMO was successfully expanded from conjugated styrene derivatives to non-conjugated alkenes, especially a-substituted secondary allylic alcohols, affording enantiopure epoxides. Most significantly, cascade reactions involving ketoreductase and SMO were designed, which resulted in glycidol derivatives or epoxy ketones with excellent enantio- and diastereo-selectivity using a, $\beta$-unsaturated ketones as the substrates. In addition, mutants of SMO with altered substrate preference and enhanced activity were constructed, which indicated great potential of SMO for further improvement.
\end{abstract}

Keywords: Epoxidation, Styrene monooxygenase, Pseudomonas, Chiral epoxide, Cascade reaction

\section{Background}

Enantiopure epoxides are extremely versatile building blocks in organic synthesis and pharmaceutical industry (Lin et al. 2011a; Sharpless 2002). Although numerous chemo-catalyzed asymmetric epoxidations have been developed in the last few decades, biocatalytic epoxidation serves as a strong candidate for preparing single enantiomeric epoxides, especially starting from nonfunctional terminal alkenes. Several kinds of enzymes, such as styrene monooxygenase (SMO), xylene monooxygenase (XMO), alkene/alkane monooxygenase, chloroperoxidase, etc., have been reported to catalyze asymmetric epoxidation. Among them, SMOs (EC 1.14.14.11) display exceptional enantioselectivity that is very attractive for preparing single enantiomeric epoxides (Bernasconi et al. 2000; Lin et al. 2010, 2011a; Schmid et al. 2001).

\footnotetext{
*Correspondence: wuzhl@cib.ac.cn

${ }^{1}$ Key Laboratory of Environmental and Applied Microbiology, Chengdu Institute of Biology, Chinese Academy of Sciences, 9 South Renmin Road, 4th Section, Chengdu 610041, Sichuan, People's Republic of China Full list of author information is available at the end of the article
}

SMOs catalyze the transformation of styrene into $(S)$ styrene oxide in the upper metabolic pathway of styrene degradation (Mooney et al. 2006). They are mostly twocomponent flavin-dependent monooxygenase composed of a FAD-dependent styrene epoxidase and a NADHdependent flavin reductase (StyB), encoded by sty $A$ and $s t y B$ genes (Otto et al. 2004). Besides the two-component SMOs, several self-sufficient one-component SMOs have been isolated from Rhodococcus opacus (Tischler et al. 2012), and a novel styrene monooxygenase SmoA isolated from metagenome as well (Van Hellemond et al. 2007). Most SMOs reported so far originate from Pseudomonas and Rhodococcus species, sharing high sequence similarities (Bae et al. 2010; Lin et al. 2010; Mooney et al. 2006; Otto et al. 2004; Toda et al. 2012).

When overexpressed in Escherichia coli, SMOs are able to catalyze the epoxidation of styrene to afford $(S)$-styrene epoxide with $>99 \%$ ee (Bernasconi et al. 2000; Otto et al. 2004). Particularly, the SMO from Pseudomonas taiwanensis VLB120 (Volmer et al. 2014) has been successfully scaled up in the production of enantiopure $(S)$ styrene oxide (Panke et al. 2002). Further investigation 
has expanded its substrate spectrum to styrene derivatives and analogs (Lin et al. 2011c; Liu et al. 2015), as well as aliphatic olefins (Toda et al. 2015). Compared with classic chemo-catalysts and hydrolytic kinetic resolution to achieve optically pure styrene oxide, SMO catalyzes the epoxidation of styrene and derivatives with exquisite regio- and enantioselectives under moderate reaction conditions, providing an attracting alternative for the synthesis of chiral epoxides (Bernasconi et al. 2000; Lin et al. 2010; Schmid et al. 2001).

This account focuses on the continuous effort of our research group on the isolation, application, and improvement of an SMO from Pseudomonas sp. LQ26. The work began with the traditional isolation of microorganism from environmental samples, and led to some interesting discoveries to synthesize chiral epoxides with varied structures that have expanded the scope of bioepoxidation reactions.

\section{Isolation of styrene upper catabolic genes from Pseudomonas sp. LQ26}

The styrene degrading strain was isolated by plating a styrene-enriched active sludge sample on agar plates containing 4-chloroindole based on the known indigoforming capacity of SMOs (Panke et al. 1998; Van Hellemond et al. 2007). The compound 4-chloroindole had been used in our previous work in the directed evolution of cytochrome P450 2A6, and proved a better substrate than indole for library screening because of enhanced color development (Zhang et al. 2009). The strain was designated Pseudomonas sp. LQ26 based on 16s rDNA analysis. It was able to use styrene and styrene oxide as sole carbon sources, and its SMO activity was inducible by the addition of styrene (Lin et al. 2010).

The sty $A B$ gene of Pseudomonas sp. LQ26 showed a maximum of $79 \%$ sequence identity with other styABs. It appeared as the most distant member of all SMOs originating from the genus of Pseudomonas (Lin et al. 2010). Genomic walking upstream and downstream of sty $A B$ gene of Pseudomonas sp. LQ26 revealed the same arrangement of open reading frames (ORF) as described before for the styrene upper catabolic pathway (Mooney et al. 2006), with two regulatory genes styS and styR upstream, encoding a sensor histidine kinase and a response regulator, and two additional styrene catabolic genes $s t y C$ and $s t y D$ downstream encoding a styrene oxide isomerase and a phenylacetaldehyde dehydrogenase.

The comparison of individual styrene catabolic ORFs from Pseudomonas sp. LQ26 with others in the genus of Pseudomonas is shown in Table 1. The sizes of the six genes (styS, styR, styA, styB, styC, styD) were the same as previously reported (The 7641-bp genomic sequence of stySRABCD has been deposited at GeneBank under accession no. GU593979). Their identities ranged from 72 to $80 \%$ at DNA level and $80-91 \%$ at protein level. The sequence alignments demonstrated that each gene in the styrene catabolism upper pathway in Pseudomonas sp. LQ26 was the most distant member of all originating from the genus of Pseudomonas, and the conserved operonic structure suggested a common evolutionary origin for this catabolic cluster.

\section{Asymmetric epoxidation of styrene derivatives and analogs}

The isolated sty $A B$ gene of Pseudomonas sp. LQ26 was expressed in recombinant $E$. coli, and the whole cells harboring the SMO were applied to the epoxidation of a spectrum of styrene derivatives and analogs in a bis(2ethylhexyl) phthalate (BEHP)/aqueous biphasic system, which is known to facilitate in situ product extraction and substrate supply to alleviate the product/substrate inhibition (Panke et al. 2002).

The results showed that the SMO could catalyze the epoxidation of a broad range of conjugated aromatic alkenes with varied skeletons, affording the corresponding $(S)$-epoxides with excellent enantiomeric excesses (>99\%) at up to $100 \%$ conversions (Fig. 1). However,

Table 1 Comparison of styrene catabolic ORFs from Pseudomonas sp. LQ26 ${ }^{\mathrm{a}}$ with others in the genus of Pseudomonas

\begin{tabular}{|c|c|c|c|c|c|c|}
\hline \multirow[t]{2}{*}{ Strains } & \multicolumn{6}{|c|}{ Protein identity (\%) } \\
\hline & stys & styR & styA & styB & styC & styD \\
\hline P. putida SN-1 & - & - & 87 & 85 & 89 & 86 \\
\hline P. fluorescens ST & 80 & 85 & 89 & 84 & 89 & 87 \\
\hline P. sp. Y2 & 80 & 86 & 88 & 85 & 91 & 86 \\
\hline P. taiwanensis VLB120 & - & 86 & 89 & 85 & 88 & 84 \\
\hline P. putida CA-3 & - & - & 88 & 85 & - & - \\
\hline
\end{tabular}

a The strain was deposited at China Center for Type Culture Collection (Wuhan, China) under the acquisition number of CCTCC M2010188

b Identities were generated using BLAST with the discontiguous megablast mode 


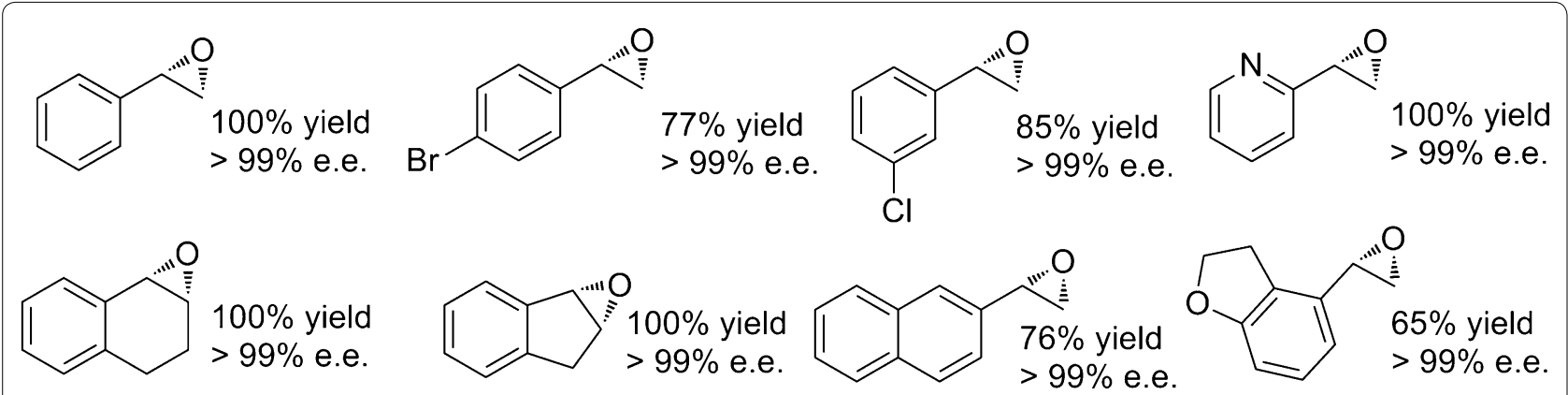

Fig. 1 Enantiopure epoxides produced from SMO-catalyzed epoxidation of conjugated aromatic alkenes. Shown are the HPLC yields and enantiomeric excesses of the corresponding epoxides

electron-withdrawing group and bulky groups appeared unfavorable for the reaction. Bromo- and chlorosubstituted substrates afforded lower product yields. Bulky alkenes such as $(E)$-stilbene, or compounds with electron-withdrawing group directly connected to the terminal alkene, such as $(E)$-4-phenylbut-3-en-2-one, $(E)$ 1-(3-chloroprop-1-enyl) benzene, and (E)-1-(2-nitrovinyl)benzene were not accepted as substrates of the SMO (Lin et al. 2010, 2011b).

Furthermore, the bio-epoxidation of a series of styrene derivatives with substituents ranging from $\mathrm{H}$ to propyl demonstrated a significant steric effect (Table 2). Substituents at the $\mathrm{R}^{3}$ position appeared to be unfavorable in all the cases tested. Substrates with a bulky substituent apparently showed lower activities. Substituents at the $\alpha$-position $\left(R^{1}\right)$ caused greater steric hindrance than those at the $\beta$-position $\left(\mathrm{R}^{2}\right)$, and the $(E)$-isomers of substituent $\mathrm{R}^{2}=\mathrm{Et}$ and $\mathrm{R}^{2}=n$-pr performed much better than the corresponding (Z)-isomers (Table 2) (Lin et al. 2011b).

\section{Asymmetric epoxidation of allylbenzene derivatives}

The SMO from Pseudomonas sp. LQ26 was found to catalyze the epoxidation of non-conjugated alkenes, yielding the corresponding $(S)$-epoxides with low to moderate enantiomeric excesses (Fig. 2) (Lin et al. 2010). Despite the low selectivity, this is the first report on the epoxidation of non-conjugated alkenes catalyzed by SMO. For the substrate 1-allylbenzene, the bio-epoxidation yielded product with $36 \%$ ee. A recent report also showed that the SMOs from Rhodococcus sp. ST-5 and ST-10 catalyzed the same substrate to the corresponding epoxides with 76.2 and $65.7 \%$ ee, respectively (Toda et al. 2012).

Inspired by the positive impact of the hydroxyl group to the chiral recognition (Fig. 2), we subsequently applied the SMO to the kinetic resolution of $\alpha$-substituted secondary allylic alcohols, and achieved excellent enantio- and diastereo-selectivity, generating a spectrum of
Table 2 Stereoselective biotransformation of styrene<smiles>[R]C([R])=C([R])c1ccccc1</smiles>

derivatives

\begin{tabular}{lllc}
\hline Entry & Substrate & Relative activity (\%) & ee (\%) \\
\hline 1 & Styrene $(\mathbf{1 a})$ & 100 & $>99$ \\
2 & $\mathrm{R}^{2}=\mathrm{Me}(\mathbf{2 a})$ & 97 & $>99$ \\
3 & $\mathrm{R}^{1}=\mathrm{Me}(\mathbf{3 a})$ & 93 & $>99$ \\
4 & $\mathrm{R}^{2}, \mathrm{R}^{3}=\mathrm{Me}(\mathbf{4 a})$ & 71 & $>99$ \\
5 & $\mathrm{R}^{2}=-\mathrm{CH}=\mathrm{CH}_{2}(\mathbf{5 a})$ & 64 & 96 \\
6 & $\mathrm{R}^{2}=\mathrm{Et}(\mathbf{6 a})^{\mathrm{a}}$ & 51 & $>99$ \\
7 & $\mathrm{R}^{3}=\mathrm{Et}(\mathbf{7 a})^{\mathrm{a}}$ & 10 & $>99$ \\
8 & $\mathrm{R}^{1}=\mathrm{Et}(\mathbf{8 a})$ & 39 & $>99$ \\
9 & $\mathrm{R}^{2}=n-\operatorname{Pr}(\mathbf{9 a})^{\mathrm{b}}$ & 15 & $>99$ \\
10 & $\mathrm{R}^{3}=n-\operatorname{Pr}(\mathbf{1 0 a})^{\mathrm{b}}$ & 3 & $>99$ \\
11 & $\mathrm{R}^{2}=i-\operatorname{Pr}(\mathbf{1 1 a})$ & 15 & $>99$ \\
12 & $\mathrm{R}^{1}=n-\operatorname{Pr}(\mathbf{1 2 a})$ & 7 & $>99$ \\
\hline
\end{tabular}

added as a mixture with 6a:7a $=$ 1:0.8

b Added as a mixture with 9a:10a $=1: 0.7$

glycidol derivatives with contiguous stereogenic centers (Table 3; Fig. 3a) (Lin et al. 2011c). In all cases, (S)-allylic alcohols were the preferred enantiomers to undergo the epoxidation, which is consistent with the selectivity of SMO towards conjugated styrene derivatives. Over $99 \%$ enantiomeric excesses were achieved in most cases with varied reactivity and diastereomeric ratio. The biotransformation was greatly affected by the position of the substituents. Substituents at ortho-positions strongly prevented the reaction with no epoxide formation observed for $o$-fluoro- or $o$-methyl-substituted substrates. Electron-withdrawing groups also negatively impacted the reactivity (Table 3 , entries $2-7$ ). 


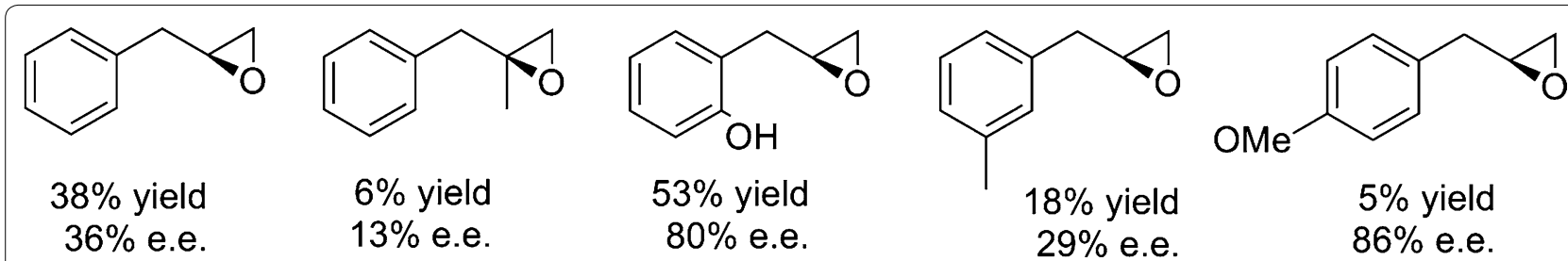

Fig. 2 Enantiopure epoxides produced from SMO-catalyzed epoxidation of non-conjugated alkenes. Shown are the HPLC yields and enantiomeric excesses of the corresponding epoxides

Table 3 Comparison of two methods in the production of chiral glycidol derivatives

\begin{tabular}{|c|c|c|c|c|c|c|c|}
\hline \multirow[t]{2}{*}{ Entry } & \multirow[t]{2}{*}{$\mathrm{R}=$} & \multicolumn{3}{|l|}{ Method $1^{a}$} & \multicolumn{3}{|l|}{ Method $2^{\mathrm{a}}$} \\
\hline & & Yield (\%) & ee (\%) & $d r$ & Yield (\%) & ee (\%) & $d r$ \\
\hline 1 & $\mathrm{Ph}$ & 50 & $>99$ & $98: 2$ & $>99$ & $>99$ & $>99: 1$ \\
\hline 2 & $m-\mathrm{FC}_{6} \mathrm{H}_{4}$ & 51 & $>99$ & $96: 4$ & 97 & $>99$ & $>99: 1$ \\
\hline 3 & $p-\mathrm{FC}_{6} \mathrm{H}_{4}$ & 50 & $>99$ & $96: 4$ & 98 & $>99$ & $>99: 1$ \\
\hline 4 & $m-\mathrm{ClC}_{6} \mathrm{H}_{4}$ & 42 & 97 & $89: 11$ & 83 & $>99$ & $>99: 1$ \\
\hline 5 & $p-\mathrm{ClC}_{6} \mathrm{H}_{4}$ & 46 & $>99$ & $>99: 1$ & 84 & $>99$ & $>99: 1$ \\
\hline 6 & $m-\mathrm{BrC}_{6} \mathrm{H}_{4}$ & 28 & 92 & $87: 13$ & 54 & $>99$ & $>99: 1$ \\
\hline 7 & $p-\mathrm{BrC}_{6} \mathrm{H}_{4}$ & 35 & $>99$ & $>99: 1$ & 64 & $>99$ & $>99: 1$ \\
\hline 8 & $m-\mathrm{MeC}_{6} \mathrm{H}_{4}$ & 48 & $>99$ & $98: 2$ & 87 & $>99$ & $>99: 1$ \\
\hline 9 & $p-\mathrm{MeC}_{6} \mathrm{H}_{4}$ & 50 & 98 & $>99: 1$ & 86 & $>99$ & $>99: 1$ \\
\hline 10 & $m-\mathrm{OMeC}_{6} \mathrm{H}_{4}$ & 17 & $>99$ & $92: 8$ & 37 & $>99$ & $>99: 1$ \\
\hline 11 & $p-\mathrm{OMeC}_{6} \mathrm{H}_{4}$ & 17 & $>99$ & $98: 2$ & 75 & $>99$ & $>99: 1$ \\
\hline 12 & 2-thienyl & 58 & 98 & $62: 38$ & 79 & $>99$ & $96: 4$ \\
\hline 13 & 3-thienyl & 40 & $>99$ & $92: 8$ & 98 & $>99$ & $>99: 1$ \\
\hline 14 & benzyl & 25 & $>99$ & $86: 14$ & 55 & $>99$ & $>99: 1$ \\
\hline
\end{tabular}

a The schemes for Methods 1 and 2 are shown in Fig. 3. Briefly, Method 1 uses racemic allylic alcohols as the substrates and recombinant E. coli BL21 cells expressing SMO as the catalyst, and the reactions continue for $2-48 \mathrm{~h}$ at $30^{\circ} \mathrm{C}$. Method 2 uses $\alpha, \beta$-unsaturated ketones as the substrates. The bioreduction of ketones was first performed in the presence of both ChKRED03 and the GDH/glucose system. Then freshly harvested whole cells of recombinant E. coli expression SMO were added, and the incubation was continued at $30^{\circ} \mathrm{C}$ for $2-36 \mathrm{~h}$

${ }^{b}$ Determined via reverse-phase HPLC analysis, and defined as (moles of product formed)/(moles of total added substrate)

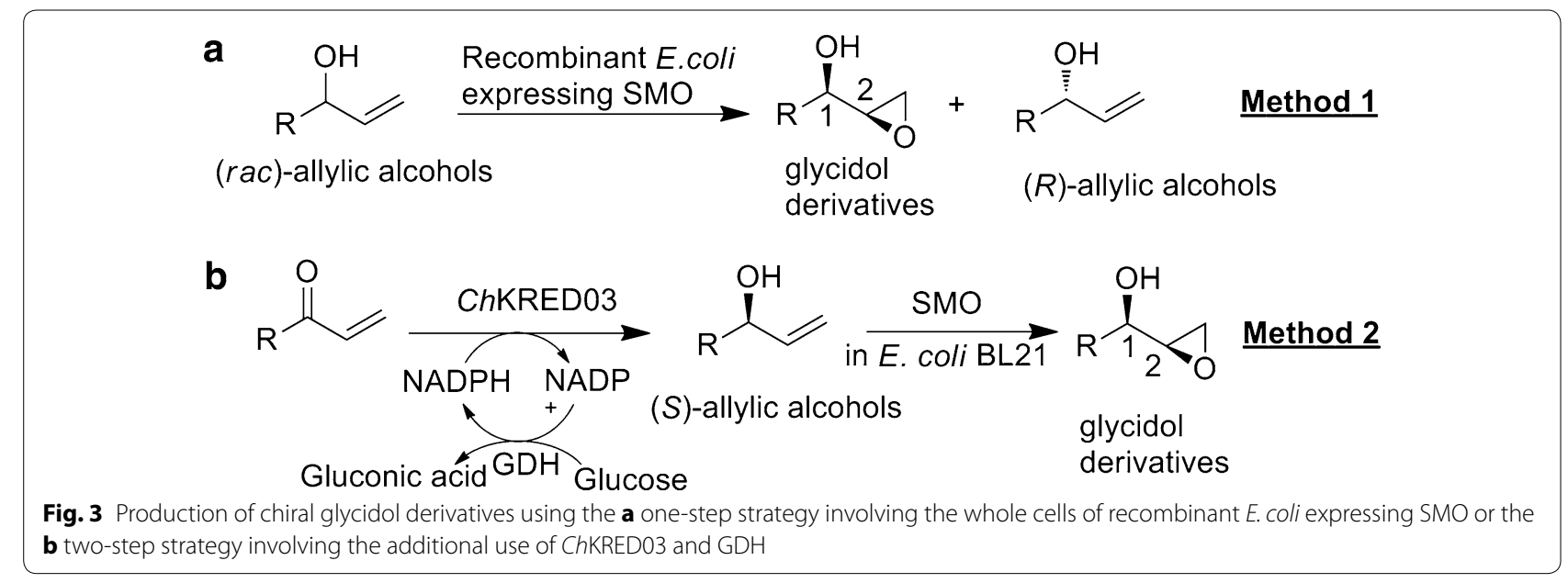


For racemic 1-phenylprop-2-enol (Entry 1), the product $(1 R, 2 R)$-phenyl glycidol was achieved in $2 \mathrm{~h}$ with excellent enantioselectivity (ee > $99 \%$ ) and diastereoselectivity (dr 98:2) at the maximum theoretical yield of $50 \%$. The remaining $(R)$-isomer was recovered with $>99 \%$ ee without further transformation. The result showed clear advantage of the enzymatic method over previously established chemistry methods, such as the Sharpless epoxidation and vanadium-based method (Zhang et al. 2005), which required up to 12 days for the same substrate to reach $50 \%$ conversion, and yielded the epoxide with $90-93 \%$ ee.

\section{Cascade reactions involving SMO and ketoreductase}

In order to overcome the low theoretical yield of kinetic resolution of secondary allylic alcohols, we designed a one-pot two-step enzymatic cascade starting from prochiral $\alpha, \beta$-unsaturated ketones using an $S$-specific ketoreductase ChKRED03 and SMO (Fig. 3b). ChKRED03 was a putative ketoreductase mined from the genome of Chryseobacterium sp. CA49 (Liu et al. 2014). In this cascade reaction, ChKRED03 performed the efficient bioreduction of the substrates to provide $(S)$-allylic alcohols in the presence of the GDH-catalyzed NADPH recycling system, followed by SMO-catalyzed epoxidation to achieve glycidol derivatives (Fig. 3b). Excellent enantioselectivity ( $>99 \%$ ee) and diastereoselectivity ( $\mathrm{dr}>99: 1)$ were achieved for the majority of the substrates, and the product yields reached up to $>99 \%$ (Table 3). Compared with previous results using SMO as the only catalyst, the two-step enzymatic cascade delivered much improved substrate conversion and product yield. The isolated yields reached up to $93 \%$ in a 50 -ml reaction system (Table 3 ).

For $\alpha, \beta$-unsaturated ketones, the $\mathrm{C}=\mathrm{C}$ double bond can undergo either reduction or epoxidation. The former reaction was undesired in this case, but often proceeded efficiently in the presence of $E$. coli whole cells. Therefore, we performed the knockout of the nemA gene (encoding $N$-acetyl maleimide reductase) from $E$. coli BL21 (DE3). The resulting strain of E. coli BL21 $n$ nemA showed significantly decreased ene-reductase activity toward 4-phenylbut-3-en-2-one (Liu and Wu 2016). When the carbonyl reductase READH and SMO were co-expressed in such a strain, the whole-cell system enabled a "formal" asymmetric bio-epoxidation of electron-deficient (substituted)-4-phenylbut-3-en-2-one via a tandem reduction-epoxidation-dehydrogenation cascade (Fig. 4a), yielding chiral epoxy ketones with up to $>99 \%$ ee and $>99 \%$ conversion. In the presence of excess amount of isopropanol, the main product was literally switched from epoxy ketones to allylic epoxy alcohols with excellent enantio- and diastereo-selectivity and high yield (Fig. 4b) (Liu and Wu 2016), which serve as extremely versatile intermediates with further functionalization (Hussain and Walsh 2008; Lauret 2001).

\section{Protein engineering of SMO}

Rational design was employed to engineer the SMO from Pseudomonas sp. LQ26 based on the X-ray crystal structure of the dimeric FAD-specific oxygenase subunit (StyA) of the SMO from P. putida S12 (PDB ID: 3IHM)

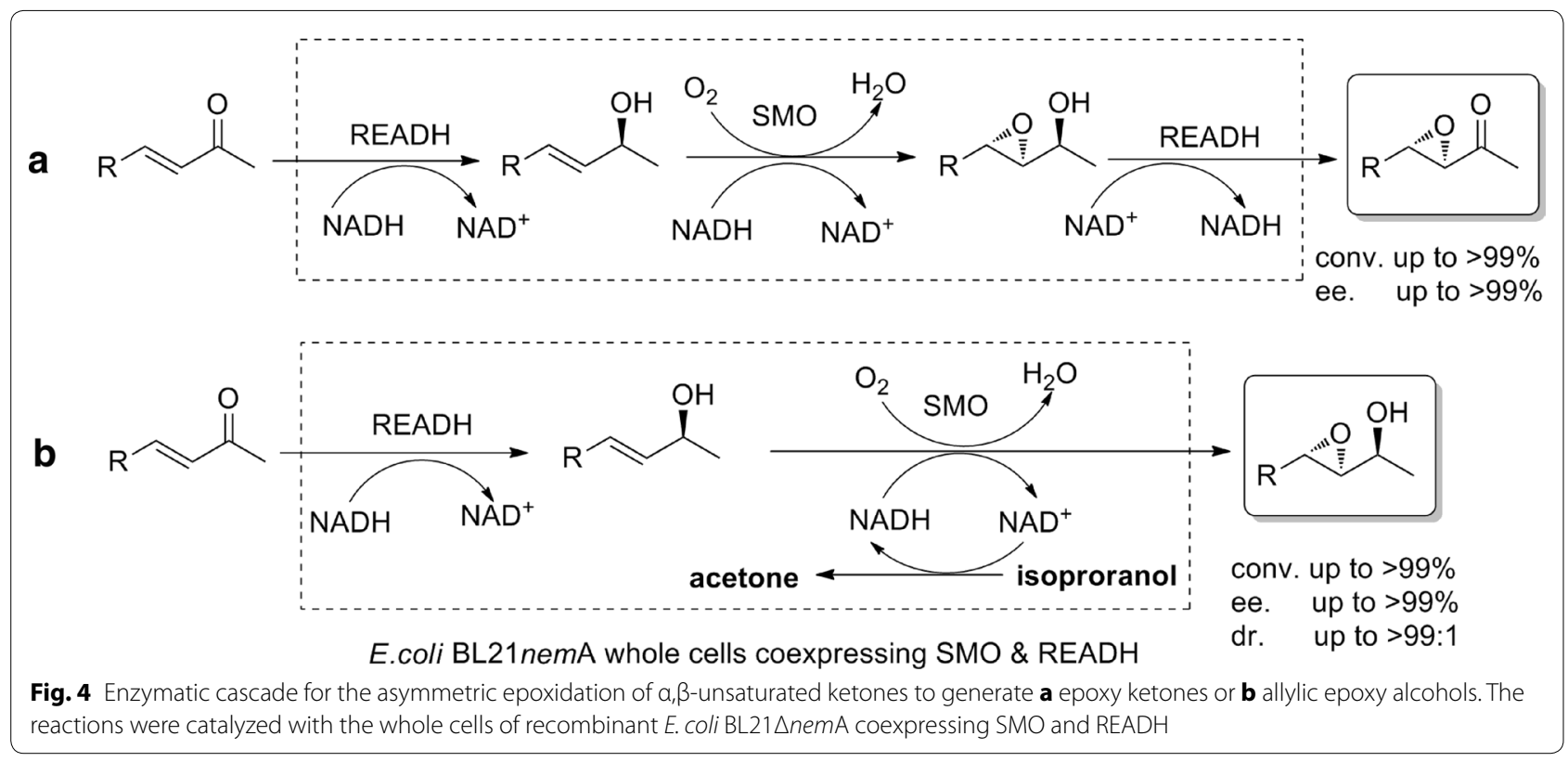


(Ukaegbu et al. 2010), which shares $89 \%$ identity at the protein level. Using molecular docking, three mutants (Y73 V, Y73F, and S96A) being adjacent to the phenyl ring of styrene have been found to exhibit higher enzymatic activities than the wild-type in the epoxidation of styrene, while retaining excellent stereoselectivity. The specific epoxidation activity of the most active mutant S96A toward styrene and trans- $\beta$-methylstyrene are $2.6-$ and 2.3 -fold of the wild-type, respectively. In addition, the Y73V mutant showed an unexpected reversal of enantiomeric preference toward 1-phenylcyclohexene (Lin et al. 2012). Sequence alignment shows that all SMOs originating from the genus Pseudomonas share the same amino acid residues at positions 73 and 96 . However, self-sufficient one-component StyA2B from $R$. opacus $1 C P$ has Ile and Ala at the corresponding positions, respectively (Tischler et al. 2012), but whether they would indicate higher activity in StyA2B is currently unknown (Lin et al. 2012).

Molecular docking of $\alpha$-ethylstyrene was also performed to identify adjacent residues, and four amino acid substitutions (R43A, L44A, L45A, and N46A) were introduced into the enzyme, leading to a change of substrate preference. The mutant L45A, in particular, exhibited an altered substrate preference toward the bulkier substrate $\alpha$-ethylstyrene (Qaed et al. 2011).

\section{Conclusion and perspective}

SMO-catalyzed bio-epoxidation reactions possess great potential for green synthesis. They utilize molecular oxygen as a clean reactant, and are routinely carried out at ambient temperature under atmospheric pressure, delivering chiral epoxides with exceptionally high chem-, regio-, and stereo-selectivity in most cases. However, many challenges remain, such as insufficient enzyme availability, narrow substrate spectrum, poor stability, and low catalytic efficiency. Our efforts on the SMO from Pseudomonas sp. LQ26 indicated that the substrate spectrum of SMO could be expanded by elaborative substrate design and protein engineering. The current investigation is focused on exploiting new "epoxygenase" and designing downstream enzymatic reactions to use the epoxides in situ, which is expected to lead to more diversified products.

\section{Authors' contributions \\ YL and YCL drafted the manuscript. ZLW modified the manuscript. All authors read and approved the final manuscript.}

\footnotetext{
Author details

${ }^{1}$ Key Laboratory of Environmental and Applied Microbiology, Chengdu Institute of Biology, Chinese Academy of Sciences, 9 South Renmin Road, 4th Section, Chengdu 610041, Sichuan, People's Republic of China. ${ }^{2}$ Environmental Microbiology Key Laboratory of Sichuan Province, Chengdu 610041, People's Republic of China. ${ }^{3}$ Graduate University of the Chinese Academy of Sciences, Beijing 100049, People's Republic of China.
}

\section{Acknowledgements}

The research was supported in part by the National Natural Science Foundation of China (20802073, 21072183, 21372216 and 21572220), the Open Fund of Key Laboratory of Environmental and Applied Microbiology (KLCAS-201306 and KLCAS-2015-01), and the 100 Talents Program and the Key Research Program (KGZD-EW-606-14) of the Chinese Academy of Sciences. We thank Hui Lin, Jing Qiao, De-Fang Tang, and Abeer Ahmed Qaed Ahmed who have participated in this work.

\section{Competing interests}

The authors declare that they have no competing interests.

Received: 24 December 2015 Accepted: 8 February 2016 Published online: 16 February 2016

\section{References}

Bae JW, Doo EH, Shin SH, Lee SG, Jeong YJ, Park JB, Park S (2010) Development of a recombinant Escherichia coli-based biocatalyst to enable high styrene epoxidation activity with high product yield on energy source. Process Biochem 45(2):147-152

Bernasconi S, Orsini F, Sello G, Colmegna A, Galli E, Bestetti G (2000) Bioconversion of substituted styrenes to the corresponding enantiomerically pure epoxides by a recombinant Escherichia coli strain. Tetrahedron Lett 41(47):9157-9161

Hussain MM, Walsh PJ (2008) Tandem reactions for streamlining synthesis: enantio- and diastereoselective one-pot generation of functionalized epoxy alcohols. Acc Chem Res 41 (8):883-893

Lauret C (2001) Epoxy ketones as versatile building blocks in organic synthesis. Tetrahedron Asymmetry 12(17):2359-2383

Lin H, Qiao J, Liu Y, Wu ZL (2010) Styrene monooxygenase from Pseudomonas sp. LQ26 catalyzes the asymmetric epoxidation of both conjugated and unconjugated alkenes. J Mol Catal B Enzym 67(3-4):236-241

Lin H, Liu JY, Wang HB, Ahmed AAQ, Wu ZL (2011a) Biocatalysis as an alternative for the production of chiral epoxides: a comparative review. J Mol Catal B Enzym 72(3-4):77-89

Lin H, Liu Y, Wu ZL (2011 b) Asymmetric epoxidation of styrene derivatives by styrene monooxygenase from Pseudomonas sp. LQ26: effects of alphaand beta-substituents. Tetrahedron Asymmetry 22(2):134-137

Lin H, Liu Y, Wu ZL (2011c) Highly diastereo- and enantio-selective epoxidation of secondary allylic alcohols catalyzed by styrene monooxygenase. Chem Commun 47(9):2610-2612

Lin H, Tang DF, Qaed AA, Liu Y, Wu ZL (2012) Mutations at the putative active cavity of styrene monooxygenase: enhanced activity and reversed enantioselectivity. J Biotechnol 161(3):235-241

Liu YC, Wu ZL (2016) Switchable asymmetric bio-epoxidation of a, $\beta$ unsaturated ketones. Chem Commun 52:1158-1161

Liu Y, Tang TX, Pei XQ, Zhang C, Wu ZL (2014) Identification of ketone reductase ChKRED20 from the genome of Chryseobacterium sp. CA49 for highly efficient anti-Prelog reduction of 3,5-bis(trifluoromethyl)acetophenone. J Mol Catal B Enzym 102(4):1-8

Liu YC, Liu Y, Wu ZL (2015) Synthesis of enantiopure glycidol derivatives via a one-pot two-step enzymatic cascade. Org Biomol Chem 13(7):2146-2152

Mooney A, Ward PG, O'Connor KE (2006) Microbial degradation of styrene: biochemistry, molecular genetics, and perspectives for biotechnological applications. Appl Microbiol Biotechnol 72(1):1-10

Otto K, Hofstetter K, Rothlisberger M, Witholt B, Schmid A (2004) Biochemical characterization of StyAB from Pseudomonas sp. strain VLB120 as a two-component flavin-diffusible monooxygenase. J Bacteriol 186(16):5292-5302

Panke S, Witholt B, Schmid A, Wubbolts MG (1998) Towards a biocatalyst for (S)-styrene oxide production: characterization of the styrene degradation pathway of Pseudomonas sp. strain VLB120. Appl Environ Microbiol 64(6):2032-2043

Panke S, Held M, Wubbolts MG, Witholt B, Schmid A (2002) Pilot-scale production of (S)-styrene oxide from styrene by recombinant Escherichia coli synthesizing styrene monooxygenase. Biotechnol Bioeng 80(1):33-41

Qaed AA, Lin H, Tang DF, Wu ZL (2011) Rational design of styrene monooxygenase mutants with altered substrate preference. Biotechnol Lett 33(3):611-616 
Schmid A, Hofstetter K, Feiten HJ, Hollmann F, Witholt B (2001) Integrated biocatalytic synthesis on gram scale: the highly enantio selective preparation of chiral oxiranes with styrene monooxygenase. Adv Synth Catal 343(6-7):732-737

Sharpless KB (2002) Searching for new reactivity (Nobel lecture). Angew Chem Int Ed 41(12):2024-2032

Tischler D, Groning JAD, Kaschabek SR, Schlomann M (2012) One-component styrene monooxygenases: an evolutionary view on a rare class of flavoproteins. Appl Biochem Biotech 167(5):931-944

Toda H, Imae R, Komio T, Itoh N (2012) Expression and characterization of styrene monooxygenases of Rhodococcus sp. ST-5 and ST-10 for synthesizing enantiopure (S)-epoxides. Appl Microbiol Biotechnol 96(2):407-418

Toda H, Ohuchi T, Imae R, Itoh N (2015) Microbial production of aliphatic (S)epoxyalkanes by using Rhodococcus sp. strain ST-10 styrene monooxygenase expressed in organic-solvent-tolerant Kocuria rhizophila DC2201. Appl Environ Microbiol 81(6):1919-1925

Ukaegbu UE, Kantz A, Beaton M, Gassner GT, Rosenzweig AC (2010) Structure and ligand binding properties of the epoxidase component of styrene monooxygenase. Biochemistry 49(8):1678-1688
Van Hellemond EW, Janssen DB, Fraaije MW (2007) Discovery of a novel styrene monooxygenase originating from the metagenome. Appl Environ Microbiol 73(18):5832-5839

Volmer J, Neumann C, Buhler B, Schmid A (2014) Engineering of Pseudomonas taiwanensis VLB120 for constitutive solvent tolerance and increased specific styrene epoxidation activity. Appl Environ Microbiol 80(20):6539-6548

Zhang W, Basak A, Kosugi Y, Hoshino Y, Yamamoto H (2005) Enantioselective epoxidation of allylic alcohols by a chiral complex of vanadium: an effective controller system and a rational mechanistic model. Angew Chem Int Ed 44(28):4389-4391

Zhang ZG, Liu Y, Guengerich FP, Matse JH, Chen J, Wu ZL (2009) Identification of amino acid residues involved in 4-chloroindole 3-hydroxylation by cytochrome P450 2A6 using screening of random libraries. J Biotechnol 139(1):12-18

\section{Submit your manuscript to a SpringerOpen ${ }^{\odot}$ journal and benefit from:}

- Convenient online submission

- Rigorous peer review

- Immediate publication on acceptance

- Open access: articles freely available online

- High visibility within the field

- Retaining the copyright to your article

Submit your next manuscript at $>$ springeropen.com 